\title{
L命NTING
}

\section{STUDIO ANIMASI DI BANJARMASIN}

\author{
Yuni Annisa Ulfatana \\ Program Studi Teknik Arsitektur Fakultas Teknik Universitas Lambung Mangkurat \\ 1610812120016@ulm.ac.id
}

Prima Widia Wastuty

Program Studi Teknik Arsitektur Fakultas Teknik Universitas Lambung Mangkurat primawidiawastuty@ulm.ac.id

\begin{abstract}
ABSTRAK
Studio animasi merupakan tempat produksi animasi. Akan tetapi produk dan fungsinya masih belum banyak diketahui masyarakat, karena itu pemakai jasa tersebut masih sedikit. Animasi tidak hanya sebagai media hiburan tapi juga sebagai media perantara yang dapat memudahkan suatu kegiatan. Sehingga dibutuhkan suatu studio animasi yang menarik dan interaktif. Pemecahan masalah yang ditawarkan yaitu dengan menggunakan metode simulasi yang bertujuan agar masyarakat lebih mudah dalam memahami animasi. Simulasi merupakan satu metode yang memperagakan sesuatu dalam bentuk tiruan yang mirip dengan keadaan yang sesungguhnya. Metode ini menggunakan pendekatan Triadic Game Design yang memiliki tiga aspek yaitu play, meaning, dan reality. Ketiga aspek inilah yang dijadikan acuan dalam merancang studio animasi.
\end{abstract}

Kata kunci: Studio animasi, simulasi, atraktif, interaktif.

\begin{abstract}
An animation studio is an animation production site. However, their products and functions are still not widely known by the public, so there are still few users of their services. The animation is not only entertainment media but also as an intermediary media that can facilitate an activity. So an attractive and interactive animation studio is needed. The solution offered is to use a simulation method that aims to make it easier for people to understand animation. Simulation is a method that shows something in a simulant form that is similar to the real situation. This method uses the Triadic Game Design approach that has three aspects, namely play, meaning, and reality. These three aspects are used as references in the animation studio.
\end{abstract}

Keyword: The animation studio, simulation, attractive, interactive. 


\section{PENDAHULUAN}

Animasi adalah gambar dari suatu objek yang dibuat seolah-olah hidup, disebabkan oleh kumpulan gambar yang berubah beraturan secara bergantian (Purnasiwi \& Kurniawan, 2013). Menurut Vaughan (2004), animasi adalah usaha yang dibuat untuk mempresentasikan sesuatu yang diam menjadi hidup. Bentuk objek yang ditampilkan dapat berupa tulisan, benda, orang, warna dan spesial efek.

Animasi sebagai suatu media yang menyampaikan sesuatu secara visual agar menjadi lebih menarik dan mendetail. Animasi digunakan dalam media hiburan, media presentasi, media iklan, media ilmu pengetahuan, media bantu, dan sebagai media pelengkap.

Animasi termasuk salah satu subsektor industri ekonomi kreatif. Industri kreatif merupakan salah satu upaya pemerintah untuk meningkatkan pendapatan ekonomi seiring berjalannya program making industri 4.0 saat ini. Program ini memberikan dampak pada kemudahan mobilitas perekonomian, akan tetapi juga berdampak pada penggunaan tenaga kerja yang semakin berkurang. Tetapi hal ini tidak berpengaruh pada industri kreatif. Sehingga industri animasi memiliki peluang yang sangat menjanjikan karena membutuhkan tenaga kerja kreatif yang banyak dalam proses pembuatannya.

Pasar utama industri animasi adalah penonton yang menikmati hasil karya animasi. Indonesia mulai fokus mengembangkan subsektor animasi yang termasuk dalam industri kreatif Indonesia pada periode 2015-2019. Pengembangan tersebut meliputi animasi berbasis komputer maupun gabungan antara komputer dan manual (Badan Ekonomi Kreatif, 2018).

Animasi di Kota Banjarmasin belum mendapatkan perhatian pemerintah setempat. Kebutuhan animasi di kota ini masih dipenuhi dari luar daerah terutama dari Pulau Jawa. Sehingga diperlukan adanya sebuah perhatian khusus dalam hal itu. Salah satunya animasi dapat membantu pemerintah dalam mengembangkan konsep smart city yaitu dengan menggunakan animasi sebagai media bantu seperti iklan, sosialisasi, pendidikan, dan layanan lainnya.

Animasi juga dapat membantu dalam memberikan konten siaran, di beberapa stasiun TV lokal yaitu TVRI, Duta TV, Banjar TV, TVRI Kalimantan Selatan, TV Majta, Kompas TV Banjarmasin, TV9 Banjarmasin, NET. Kalimantan Selatan, Prima Vision, Barito TV, Prima Tv, dan Ar Raudhah.

Studio animasi merupakan suatu wadah yang diperlukan untuk memenuhi kebutuhan animasi di Kota Banjarmasin dan sekitarnya. Kota Banjarmasin memiliki sumberdaya yang potensial di bidang animasi, yaitu dari jurusan animasi SMK Negeri 2 Banjarmasin.

Studio animasi selain menjadi wadah untuk mengembangkan hal-hal yang berkaitan dengan jasa animasi, diharapkan juga menjadi tempat bagi masyarakat untuk lebih mengenal animasi. Berdasarkan tujuan tersebut maka diperlukan suatu studio animasi yang interaktif dan atraktif, agar masyarakat merasa tertarik, memahami dan akhirnya menggunakan animasi sesuai kebutuhannya. Pada akhirnya studio ini diharapkan menjadi tempat kerja yang menyenangkan, tempat belajar, tempat mengadakan pameran, sebagai ruang publik, media pengenal dan media promosi.

\section{PERMASALAHAN}

Studio ini memiliki rumusan masalah arsitektural yaitu bagaimana rancangan studio animasi yang Interaktif dan Atraktif.

Berdasarkan tujuan dan rumusan masalah, maka yang dibutuhkan dalam mendesain studio animasi adalah rancangan studio animasi yang Interaktif dan Atraktif. Caranya dengan membuat mereka 
merasakan berada dalam dunia animasi/Animation world. Cara yang digunakan dalam penyelesaian masalah yaitu simulasi animasi dengan membuat pelaku berinteraksi melalui media animasi.

Simulasi merupakan suatu tiruan atau perbuatan berpura-pura saja (Sunaryo, 1989:137). Metode simulasi yaitu suatu cara yang mampu menciptakan kondisi nyata ke dalam kondisi yang bukan sebenarnya. Sehingga pendekatan yang tepat yaitu dengan melakukan pendekatan tematik. Pendekatan tematik yang dilakukan dengan cara mengkaji dan menerapkan tema animation world melalui produk-produk animasi kedalam arsitektur dengan cara simulasi.

\section{TINJAUAN PUSTAKA}

\section{A. Tinjauan Arsitektur}

\section{Studio Animasi}

Studio animasi merupakan suatu usaha dalam bidang jasa pembuatan animasi dan ilustrasi (Rachmawatie et al., 2016). Studio animasi memiliki kontribusi dalam perkembangan animasi di Indonesia. Beberapa contoh studio animasi tersebut seperti Lanting Animation, Kumata Animation Studio, BASE Studio, Infinite Frameworks, MSV Pictures, Studio Kasatmata, dan Tampar Production. (Whiteboard Journal, Deretan Studio Animasi di Indonesia, 2018). Studio animasi dalam menjalankan usahanya dibagi menjadi beberapa kriteria yaitu:

Tabel 1. Kriteria Studio Animasi Menurut Bekraf (diolah)

\begin{tabular}{|l|l|}
\hline $\begin{array}{l}\text { Kriteria } \\
\text { Studio } \\
\text { animasi }\end{array}$ & Layanan/Jasa \\
\hline
\end{tabular}

\begin{tabular}{|l|ll|}
\hline Kriteria mikro & 1) $\begin{array}{l}\text { Jasa membuat asset } \\
\text { 3D modelling } \\
\end{array}$ & 2) $\begin{array}{l}\text { Jasa pembuatan } \\
\text { animasi 2D atau 3D }\end{array}$ \\
\hline Kriteria kecil & 1) $\begin{array}{l}\text { Jasa pembuatan } \\
\text { storyboard pembuatan }\end{array}$ \\
& 2) $\begin{array}{l}\text { Jasa } \\
\text { layout artist }\end{array}$ \\
& 3) $\begin{array}{l}\text { Jasa pembuatan } \\
\text { asset 3d modelling }\end{array}$ \\
& 4) $\begin{array}{l}\text { Jasa pembuatan 2D } \\
\text { atau 3D animasi }\end{array}$ \\
\hline Kriteria & 1) Film animasi \\
menengah & 2) Broadcasting animasi \\
& 3) Edukasi animasi \\
& 4) Games animasi \\
& 5) Publishing animasi \\
\hline
\end{tabular}

Sumber: Panduan Pendirian Usaha Animasi (Rahmawati et al., 2016)

Pelaku usaha studio animasi kriteria kecil dalam proses produksi dan pembelajaran, minimal memiliki atau menggunakan hardware PC dan laptop Intel Core i5, Intel core i7, MOCAP (motion capture), dan penstyles.

Studio animasi ini termasuk dalam kategori kecil karena layanan dan jasa yang ditawarkan dan keahlian yang terbatas. Selain itu dilihat dari jasa dan produk yang dihasilkan, serta kemampuan pekerja. Selain itu dalam studio ini juga memuat workshop yang berfungsi sebagai tempat belajar siswa serta masyarakat umum.

\section{Pengelompokkan Ruang}

Sebelum membuat denah dan melakukan pembagian zona, pada gambar bentuk yang sudah ada, Terlebih dahulu menentukan pengelompokkan ruang berdasarkan zona.

- Zona Penunjang

$\circ$ Ruang Pimpinan
$\circ$ Ruang Administrasi
$\circ$ Toilet
$\circ$ Ruang Admisi dan Promosi
$\circ$ Ruang Baca


- Ruang Ibadah

- Ruang Informasi dan Teknologi

(IT)

Lobby

- Ruang Konsultasi

- Front Office

- Zona Komersil
- Café
o Dapur

\section{- Zona Pra Produksi}

○ Ruang Diskusi

- Ruang Lead Animator

- Ruang Storyboard

\section{- Zona Produksi}

- Ruang Gambar Manual

○ Ruang Tracing

- Studio Modelling

- Ruang Visual Effect

- Ruang Coloring/Rendering

- Studio Property

- Studio Kosong

- Zona Pasca Produksi

- Ruang Editor/ Composite Artis

- Studio Musik / Rekaman

- Ruang Percetakan \& Pemasaran

○ Ruang Rapat

○ Ruang Arsip

\section{- Ruang Publik}
- Galeri Animasi
- Ruang Serbaguna
o Teater mini

\section{- Service}

○ Ruang CCTV

- Ruang Cleaning Service

- Gudang

- Ruang Loker

- Ruang Pompa

o Ruang Genset

- Area Parkir
○ Motor
○ Mobil
- Sirkulasi

\section{B. Tinjauan Konsep}

Tema dari studio animasi ini yaitu Animation world. Animation world berarti suasana di dalam bangunan yang merepresentasikan dunia animasi yang mana pelaku menjadi tokoh/karakter di dalamnya. Sehingga dibutuhkan ruang yang atraktif dan interaktif untuk mencapai suasana itu. Hal ini dapat dilakukan dengan menerapkan teknologi animasi dalam bangunan. Teknologi yang diterapkan berupa produk dari animasi, seperti Virtual Reality (VR), hologram, Video Mapping, dll. Cara untuk menerapkan produk animasi yaitu dengan menggunakan program simulasi.

Atraktif merupakan perilaku yang berbeda-beda pada setiap manusia dan dipengaruhi oleh pengalaman yang dialaminya. Bangunan yang menciptakan atraksi melalui animasi sehingga membuat pengalaman baru bagi pengunjung atau pelaku di dalamnya. Pengalaman dibagi menjadi:

- Atraktif aktif yaitu ketertarikan kepada sesuatu yang berupa visual, auditori, dan warna memberikan efek berupa suatu perasaan yang timbul dan meluap-luap.

- Atraktif Pasif, yaitu ketertarikan kepada suatu visual, auditori, dan warna yang diperoleh dari hasil pengalamannya dan memberikan dampak pada perasaan tenang, damai, dan santai.

Interaktif identik dengan komunikasi yang dilakukan dua arah atau lebih dari komponen-komponen komunikasi. Menurut seorang pakar teknologi dan komunikasi interaktif, Esther Dyson mengungkapkan dua pengertian dari interaktif:

- Berinteraksi dengan media televisi, CD, komputer, internet, dan telepon.

- Berinteraksi dengan sesama manusia lain.

Sehingga untuk mewujudkan atraktif dan interaktif dalam bangunan tersebut 
menggunakan metode simulasi produk-produk animasi. Teknologi ini menawarkan animasi yang menarik sehingga terjadilah interaksi antara pelaku, bangunan dan animasi.

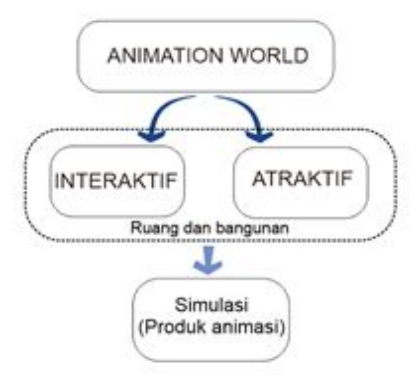

Gambar 1. Diagram Metode

Sumber: Analisis Pribadi (2020)

Metode simulasi dalam penerapannya menggunakan pendekatan Triadic Game Design yang dikembangkan oleh Casper Harteveld. Konsep Triadic Game Design ini memerlukan beberapa aspek yang harus diperhatikan, yaitu Reality, Meaning, and Play.

\section{PEMBAHASAN}

\section{A. Lokasi}

Lokasi tapak yang dipilih untuk studio animasi ini berada di Kota Banjarmasin yaitu di Jl. Let. Jend. S. Parman No.01, Belitung Utara, Kec. Banjarmasin Bar., Kota Banjarmasin, Kalimantan Selatan.

- Batas Utara : MA-KAN x French Toast dan rumah penduduk

- Batas Timur : Rumah penduduk

- Batas Barat : Aura Optikal, Toko Mebel Elizabeth, dan Jl. Let. Jend. S. Parman

- Batas Selatan : Rumah makan mama Intan dan perempatan

- Luas Lahan : 2538,3 $\mathrm{m}^{2}$

- Kontur : Datar (rawa)
- KDB

: maksimum $80 \%$

- $\mathrm{KDH}: 20 \%$

- KLB : di atas 7 lantai harus dengan persyaratan tertentu

- GSB :8,00M

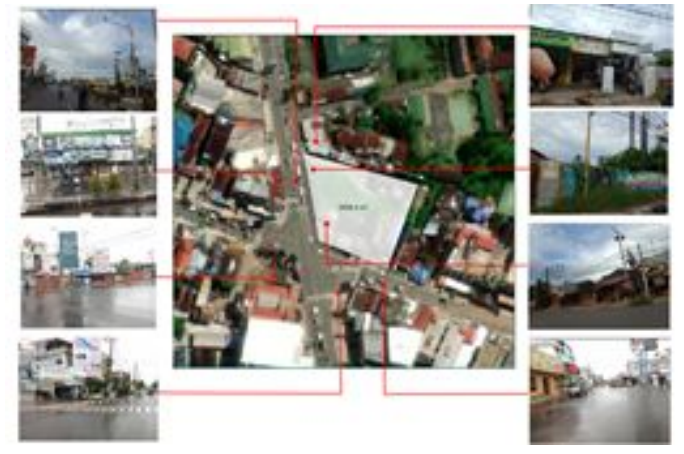

Gambar 2. Lokasi Tapak dan Penampakan sekitarnya

Sumber: Google Maps (diolah) (2020)

Lokasi ini dipilih karena memiliki karakteristik dan kelebihan yang sesuai dengan persyaratan untuk studio animasi yaitu:

- Lokasi berada di pusat kota sehingga memiliki kecepatan Internet yang memadai.

- Lingkungan yang aman, karena dekat dengan Kawasan Pertahanan Negara.

- Lokasi yang berada di lokasi perdagangan dan jasa.

- Mudah dijangkau karena berada dekat perempatan sehingga dapat diakses dari empat arah.

\section{B. Konsep Rancangan}

\section{Konsep program}

Tema animation world ditawarkan studio animasi untuk menyelesaikan permasalahan studio animasi yang interaktif dan atraktif. Sedangkan dalam penerapannya menggunakan metode simulasi, seperti gambar dibawah ini. 


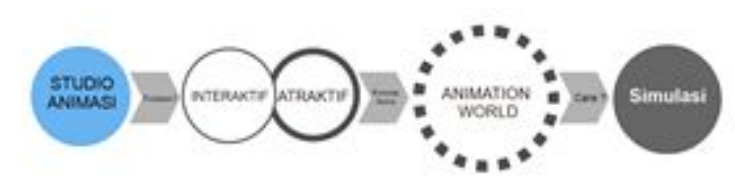

Gambar 3. Konsep program

Sumber: Analisis Pribadi (2020)

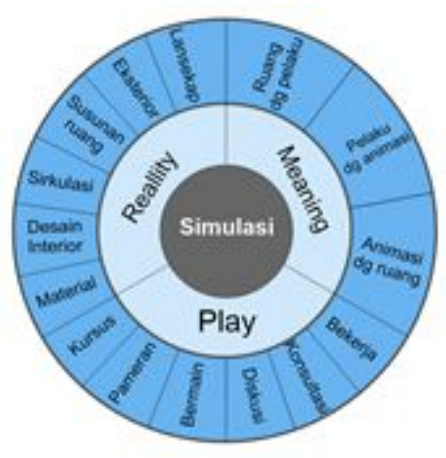

Gambar 4. Detail penerapan simulasi Sumber: Analisis Pribadi (2020)

Berikut ini penjelasan penerapan simulasi dalam bangunan. Simulasi dibagi menjadi tiga bagian yaitu:

- Reality yang diterapkan pada susunan ruang, desain bangunan dan interior yang mendukung animasi dengan menerapkan ruang atau bangunan yang dapat menunjukkan rekaman atau produk animasi melalui simulasi. Hal ini dilakukan agar desain menjadi lebih menarik.

- Meaning itu hal atau interaksi yang didapat antara bangunan, pelaku, dan animasi melalui simulasi sebagai perantara.

- Play merupakan kegiatan yang terjadi didalamnya.

Sedangkan tema animation world diterapkan dengan mengambil inti dari animasi sendiri yang memiliki tiga kata kunci yaitu bagaimana pergerakannya, pengamatan dan tingkah laku yang dilakukan oleh pelaku di dalamnya. Sehingga agar tema ini dapat dirasakan saat memasuki bangunan maka berikut beberapa penerapannya:

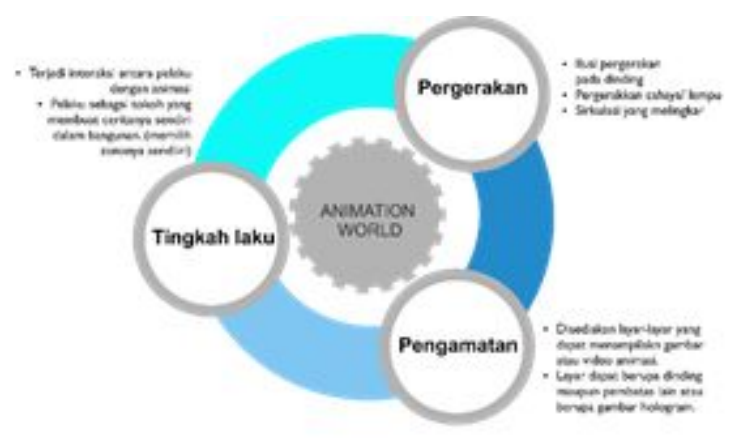

Gambar 5. Detail Penerapan Tema Animation World

Sumber: Analisis Pribadi (2020)

Penerapan tema pada bagian bagian bangunan diutamakan untuk ruangan yang berada pada lantai 1 . Ruang pada lantai ini memiliki sifat publik dan semi publik. Sedangkan penerapan pada lantai 2 lebih disesuaikan dengan kebutuhan pelaku dalam melakukan suatu pekerjaan produksi animasi.

Tabel 2. Penerapan Pada Bagian Bangunan

\begin{tabular}{|l|l|}
\hline \multicolumn{1}{|c|}{$\begin{array}{c}\text { Bagian } \\
\text { Bangunan }\end{array}$} & \multicolumn{1}{|c|}{ Penerapan } \\
\hline Dinding & Berwarna putih sebagai layar \\
\cline { 2 - 2 } & Desain ilusi \\
\cline { 2 - 2 } & Dinding layar LCD \\
\hline Perabot & Monochrome, elemen kayu \\
\hline \multirow{2}{*}{ Lantai } & $\begin{array}{l}\text { Sebagian besar warna } \\
\text { monochrome dan lantai motif } \\
\text { kayu }\end{array}$ \\
\cline { 2 - 2 } & $\begin{array}{l}\text { Setiap zona lantai dibedakan } \\
\text { dengan menggunakan material } \\
\text { lantai yang berbeda }\end{array}$ \\
\cline { 2 - 2 } & $\begin{array}{l}\text { Beberapa zona lantai juga } \\
\text { dapat disorot menggunakan }\end{array}$ \\
\hline
\end{tabular}




\begin{tabular}{|l|l|}
\hline \multirow{5}{*}{ Kolom } & animasi \\
\hline \multirow{5}{*}{ Plafon } & $\begin{array}{l}\text { Beberapa kolom dilapisi } \\
\text { material transparan yang sisi } \\
\text { bagian dalamnya diisi dengan } \\
\text { gambar yang disorot } \\
\text { menggunakan lampu untuk } \\
\text { menghasilkan ilusi bayangan. }\end{array}$ \\
\cline { 2 - 3 } & $\begin{array}{l}\text { Dilapisi dengan layar LCD } \\
\text { fleksibel }\end{array}$ \\
\hline & $\begin{array}{l}\text { Pada bagian koridor plafon di } \\
\text { desain menyerupai langit, } \\
\text { sehingga bagian ruang lain } \\
\text { terlihat lebih jelas. }\end{array}$ \\
\cline { 2 - 3 } & $\begin{array}{l}\text { Pada zona ruang publik bagian } \\
\text { langit-langit transparan untuk } \\
\text { memasukkan cahaya pada } \\
\text { bangunan bentang lebar. }\end{array}$ \\
\cline { 2 - 3 } & $\begin{array}{l}\text { Beberapa bagian langit-langit } \\
\text { disorot dengan animasi }\end{array}$ \\
\hline
\end{tabular}

Sumber: Analisis Pribadi (2020)

2. Penerapan Konsep Rancangan

a. Konsep Site dan Tapak

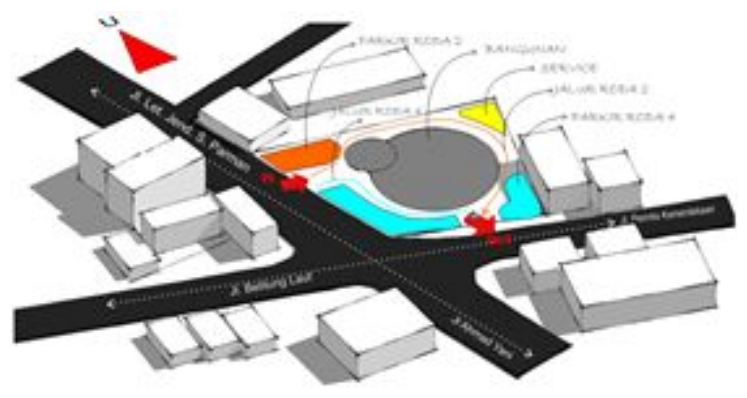

Gambar 6. Pembagian zona tapak

Gambar menunjukkan letak bangunan pada tapak yang berada pada bagian tengah tapak. Denah bangunan melingkar agar berbeda dengan bangunan sekitarnya. Tapak berada di persimpangan, sehingga terdapat dua sebagai pencapaian ke dalam tapak. Jalur masuk kedalam tapak yaitu dari Jl. Let. Jend, S. Parman. Sedangkan jalur keluar melalui Jl. Perintis Kemerdekaan.

\section{b. Konsep Bentuk Bangunan}

Konsep bentuk bangunan tetap pada tema animation world yaitu bangunan yang atraktif/menarik. Penerapan bangunan atraktif dengan bentuk dasar lingkaran. Selain bentuk lingkaran juga menjadi daya tarik jika dilihat dari bangunan sekitarnya yang berbentuk persegi.

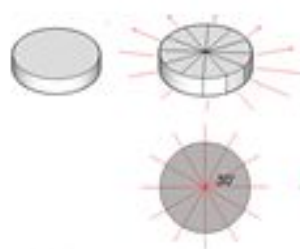

(a)

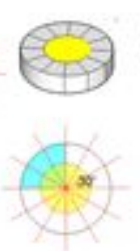

(c)

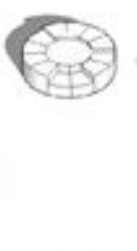

(d)

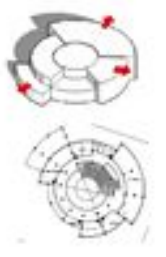

(e)
Gambar 7. Bentuk Dasar Bangunan

Bentuk dasar bangunan berupa lingkaran, kemudian lingkaran dibagi menjadi 12 bagian jari-jari dengan sudut 300 , kemudian bagian yang sudah dibagi kemudian dikelompokkan menjadi beberapa zona.

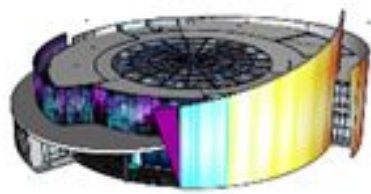

Gambar 8. Bentuk Bangunan

Bagian salah satu dinding ditinggikan sebagai penanda, agar bentuk tampak bangunan tidak membosankan. Dinding tersebut juga berperan sebagai layar sorot.

\section{c. Konsep Denah}

Setelah mendapatkan bentuk bangunan kemudian bagian denah tersebut ditentukan berdasarkan kegiatan dalam bangunan serta fungsinya yang 
dikelompokkan berdasarkan zona. Ruang dibagi berdasarkan menjadi bagian zona-zona. Kemudian urutannya menyesuaikan dengan proses produksi.

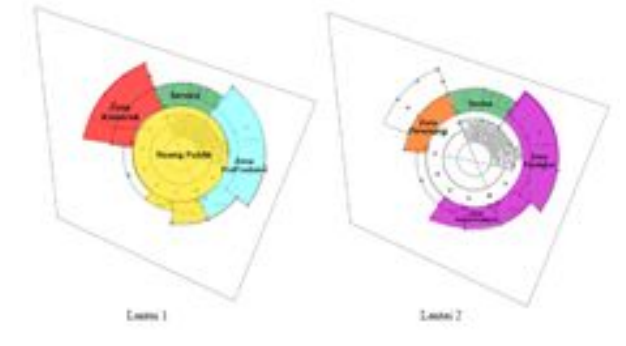

Gambar 9. Zona pembagian fungsi dalam bangunan

Zona produksi pada lantai satu ini dibagi dalam tahap praproduksi dan produksi, sehingga sifatnya lebih publik dan dapat diakses umum. Sedangkan pada lantai 2 terdapat zona produksi dan pasca produksi.

d. Konsep Interior

Konsep interior diterapkan suasana yang dibangun dengan simulasi menggunakan tiga aspek yaitu play, meaning, dan reality. Interior bangunan juga tidak lepas dari tema animation world dengan ruang yang atraktif dan interaktif.
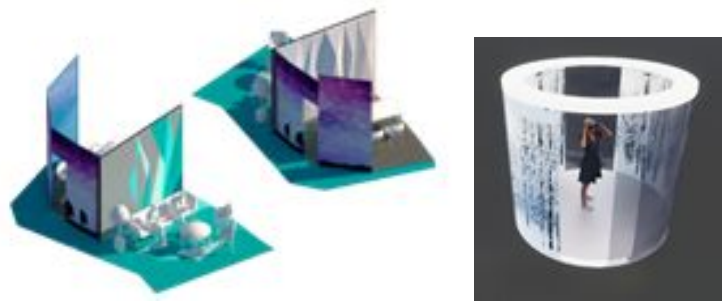

Gambar 10. Interior ruang konsultasi dan Ruang Virtual reality (VR)

Desain ruang diskusi dan konsultasi yang pada bagian dinding luar merupakan layar yang menunjukkan produk animasi. Kemudian terdapat juga ruang yang sifatnya lebih publik dengan desain dinding dan lantai dengan motif desain grafis.

Desain ruang virtual reality sebagai tempat mempromosikan animasi dengan menggunakan teknologi virtual reality (VR) atau augmented reality (AR).

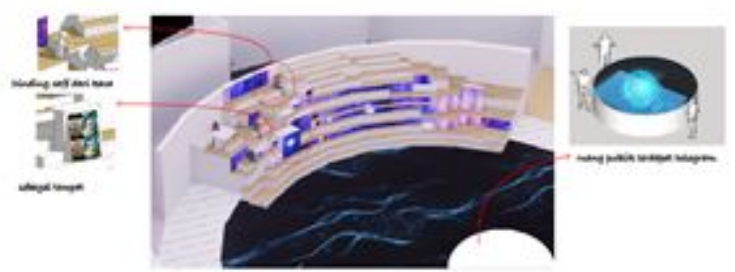

Gambar 11. Desain tangga

Penerapan interaksi bangunan dengan pelaku dan animasi, didapat dari desain tangga yang multifungsi.

\section{HASIL}

\section{A. Site Plan}

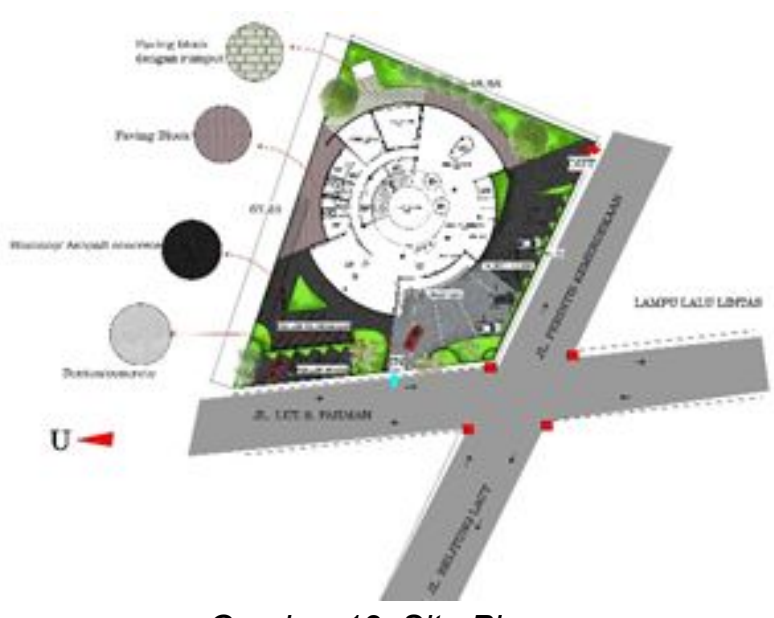

Gambar 12. Site Plan 


\section{B. Denah}

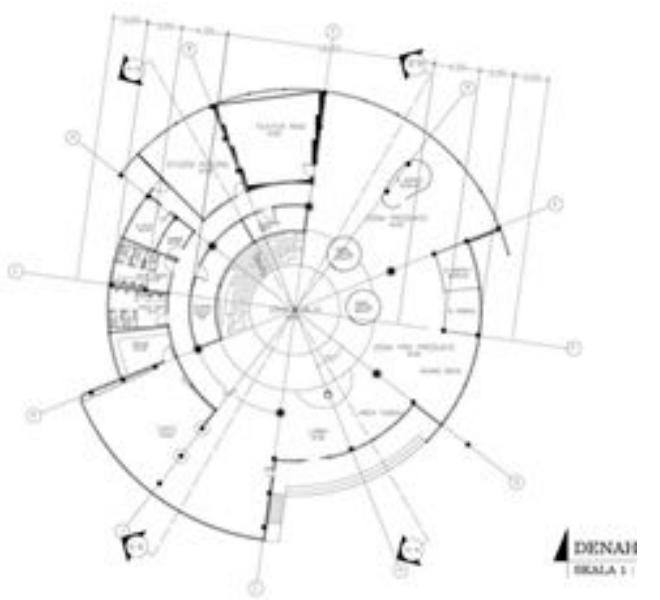

Gambar 13. Denah Lantai 1

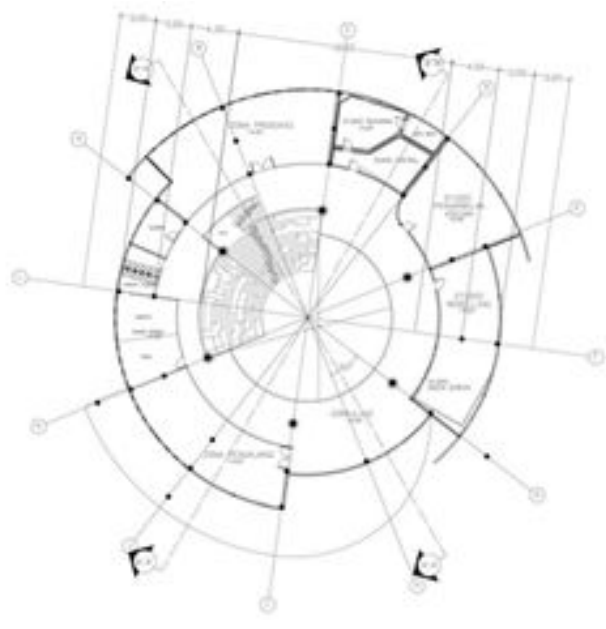

Gambar 14. Denah lantai 2

\section{Tampak}

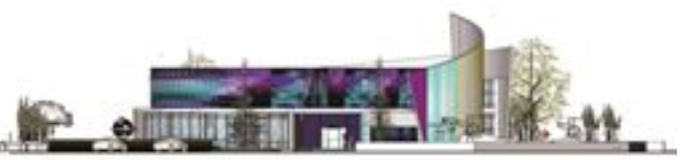

Gambar 15. Tampak Depan

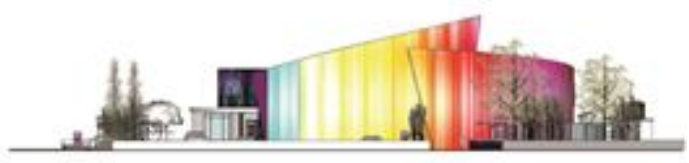

Gambar 16. Tampak Samping Kanan

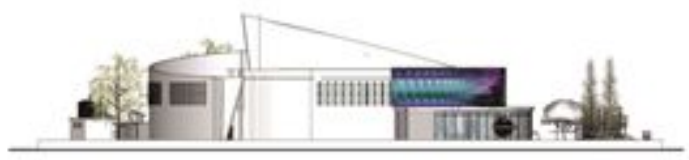

Gambar 17. Tampak Samping Kiri

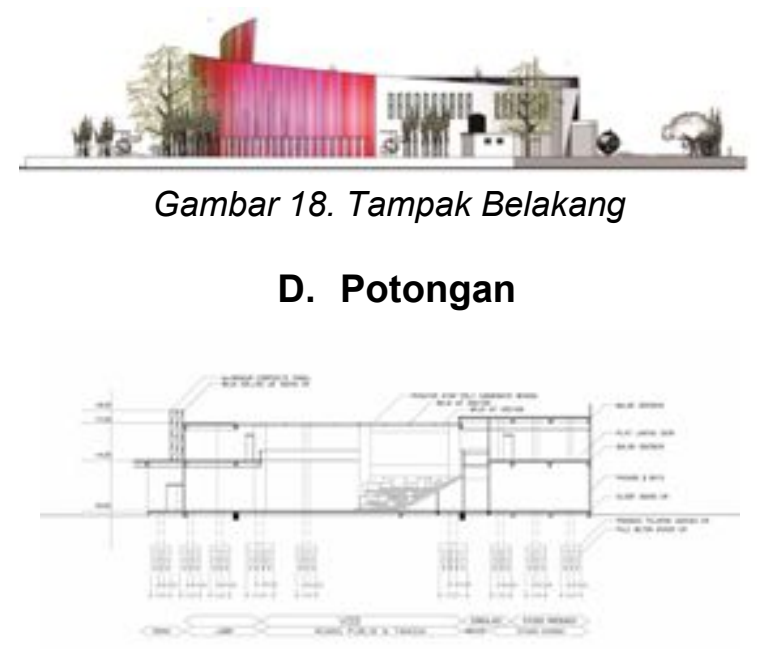

Gambar 19. Potongan A-A

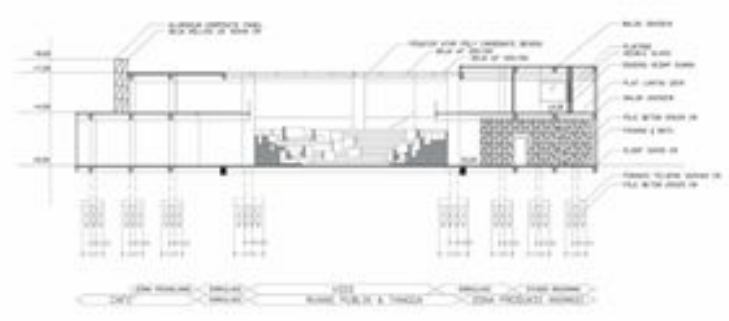

Gambar 20. Potongan B-B

\section{E. Interior}

Desain interior penerapan simulasi animasi dengan tema animation world. Mulai dari pada bagian lantai yang disorot. Bagian dinding berupa layar LED, serta pada bagian plafon dan lantai yang disorot untuk menunjukkan perbedaan zona sehingga dicapai bentuk yang interaktif. Kemudian bagian yang disorot menunjukkan sesuatu yang menarik/atraktif kepada pelaku.

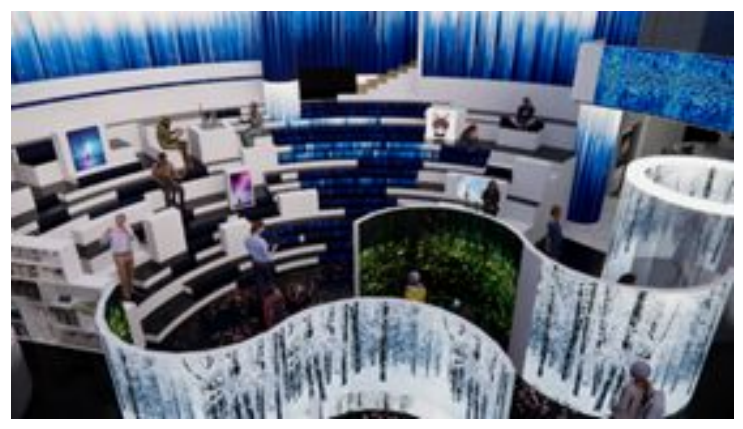

Gambar 21. Interior Ruang Publik 
Ruang publik ini dapat diakses oleh publik dan merupakan pusat dari bangunan. Fungsinya bisa menyesuaikan dengan kebutuhan seperti tempat promosi, pameran, atau diskusi.

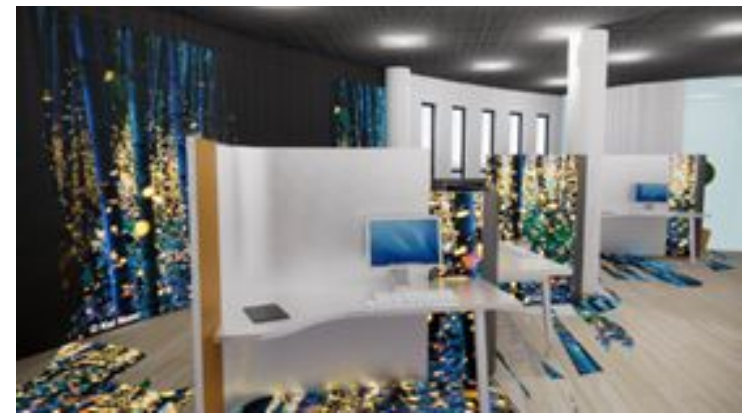

Gambar 22. Interior Ruang Kerja

Ruang ini menunjukkan penerapan interaktif yaitu pada perbedaan zona kerja dan sirkulasi, yang ditunjukkan dengan sorotan animasi pada bagian lantai.

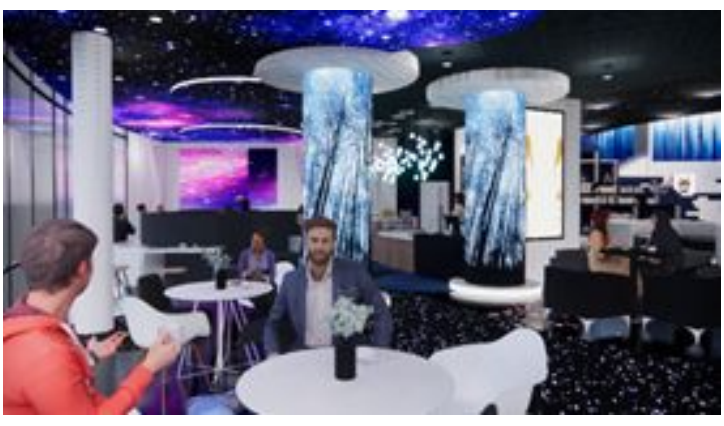

Gambar 23. Interior Café

Penerapan perbedaan zona juga diterapkan pada interior café melalui perbedaan material lantai antara sirkulasi dan zona makan. Selain itu bentuk desain kolom dibuat dengan menggunakan led fleksibel sehingga dapat menunjukkan sorotan animasi.

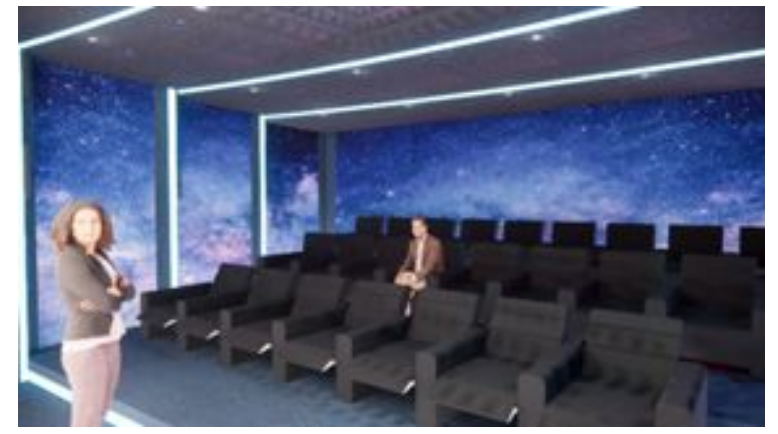

Gambar 24. Interior Teater Mini

Ruang teater mini menunjukkan simulasi seperti berada dalam kapal ruang angkasa.

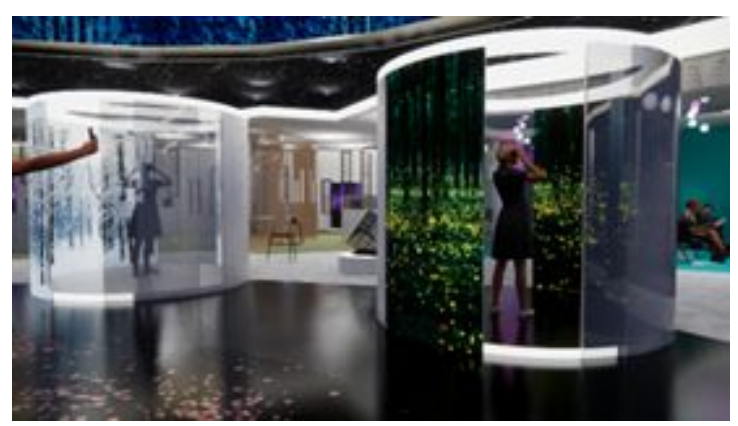

Gambar 25. Ruang Virtual Reality

Ruang yang menunjukkan simulasi langsung dari produk animasi. Serta sebagai bentuk penerapan ruang interaktif.

\section{F. Eksterior}

Eksterior bagian luar dengan bentuk atraktif yaitu pada salah satu dinding yang ditinggikan. Kemudian dinding bagian luar berupa layar led serta terdapat bagian yang disorot menggunakan animasi video mapping.

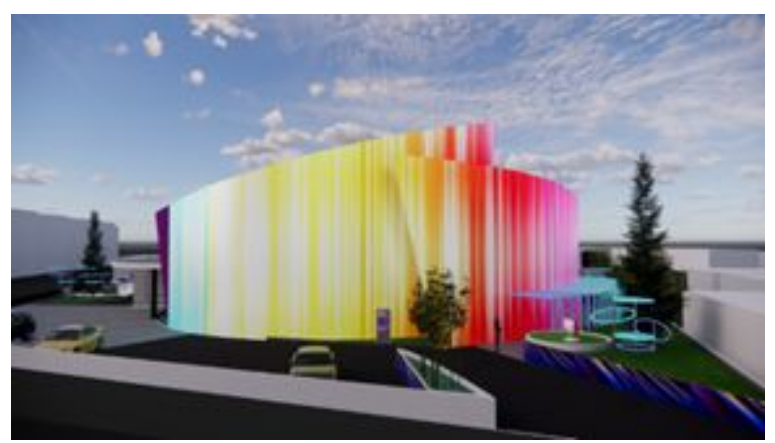

Gambar 26. Eksterior Dinding Sorot 
Penampakan dinding pada siang hari yang merupakan salah satu bentuk atraktif.

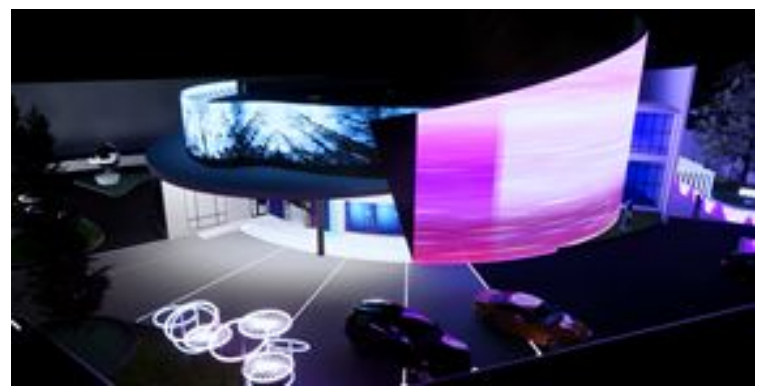

Gambar 27. Eksterior Malam Mata Burung

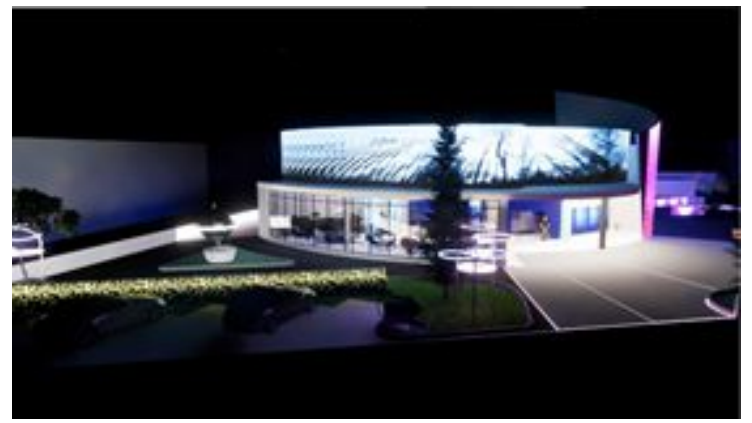

Gambar 28. Eksterior Malam

Penampakan bagian depan bagian café didesain dengan dinding kaca transparan yang berfungsi sebagai layar menunjukkan aktivitas dalam bangunan. Hal ini menunjukkan simulasi animasi yang ada dalam bangunan, yaitu pelaku sebagai tokoh dalam bangunan.

\section{KESIMPULAN}

Studio animasi selain menjadi wadah untuk mengembangkan hal-hal yang berkaitan dengan jasa animasi, diharapkan juga menjadi tempat bagi masyarakat untuk lebih mengenal animasi. Berdasarkan tujuan tersebut maka diperlukan studio animasi yang interaktif dan atraktif, agar masyarakat merasa tertarik, memahami dan akhirnya menggunakan animasi sesuai kebutuhannya.

Studio animasi yang merupakan bangunan komersil ini menawarkan solusi dengan menggunakan pendekatan tematik.
Tema yang diangkat yaitu animation world yang penerapannya menggunakan metode simulasi. Metode ini digunakan untuk mensimulasikan animasi sehingga terbentuk ruang atraktif dan interaktif.

Tema animation world diterapkan dalam bangunan dengan mengambil 3 kata kunci dari animasi yaitu bagaimana pergerakan, pengamatan dan tingkah laku yang dilakukan oleh pelaku di dalamnya. Simulasi menjadi cara dalam menerapkan tema tersebut seperti membuat suasana ruang dalam bangunan menggunakan media animasi. Simulasi dibagi menjadi tiga bagian yaitu play, meaning, dan reality.

\section{DAFTAR PUSTAKA}

\section{Referensi Buku dan Jurnal}

Badan Ekonomi Kreatif. (2013). Data Statistik dan Hasil Survey Ekonomi Kreatif. In Journal of Chemical Information and Modeling (Vol. 53, pp. 1689-1699). https://doi.org/10.1017/СВО978110741532 4.004

Badan Ekonomi Kreatif. (2018). Data Statistik dan Hasil Survei. Hasil Survei Khusus Ekonomi Kreatif, 23. Retrieved from http://www.bekraf.go.id/pustaka/page/datastatistik-dan-hasil-survei-khusus-ekonomi-k reatif

Purnasiwi, R., \& Kurniawan, M. (2013). Perancangan Dan Pembuatan Animasi 2D "Kerusakan Lingkungan" Dengan Teknik Masking. Data Manajemen Dan Teknologi Informasi (DASI), 14(3), 54.

Rachmawati, S. J., Gema, A. J., Priwanto, B., Sinaga, R., Tampubolon, S., Suryani, L., ... Endroputro, C. (2016). Panduan-Pendirian-Usaha-Animasi. Badan Ekonomi Kreatif, 1-46.

\section{Website}

Kumparan.com (2018, Februari 28) Infografik: Sumber Baru Pertumbuhan RI Itu Adalah 
Ekonomi Kreatif, edisi Kumparan Bisnis. Diambil kembali dari https://kumparan.com/kumparanbisnis/info grafik-sumber-baru-pertumbuhan-ri-itu-adal ah-ekonomi-kreatif

Media Indonesia (2018, Desember 16) kalsel kembangkan konsep smart city. Diambil kembali dari https://mediaindonesia.com/read/detail/204 530-kalsel-kembangkan-konsep-smart-city 